Guidance snags licked, others still hidden

\section{Washington}

Many fingers were crossed at a groundbreaking ceremony held at Johns Hopkins University in Baltimore, Maryland, on Monday to mark the beginning of construction work on the Space Telescope Science Institute. The construction of the Large Space Telescope itself, due to be launched from the space shuttle early in 1985 , seems just about on schedule and no major technical hurdles are foreseen.

Those who attended a programme review at the National Aeronautics and Space Administration (NASA)'s Marshall Space Flight Center two weeks ago, however, came away nervous that unanticipated problems could disrupt the delicate equilibrium in which the whole project seems to be balanced.

The Space Telescope Science Institute will be the principal observation and data analysis centre for the telescope, which will be placed in orbit 500 kilometres above the Earth's surface. It is being built on Johns Hopkins' Homewood Campus by the Association of Universities for Research in Astronomy under an initial five-year, \$24 million contract with NASA. Dr Riccardo Giacconi has been named director of the institute, which will eventually have a staff of about 150 , including between 30 and 40 astronomers from the United States and abroad.

The good news on the telescope is that the two mirrors which make up its RitcheyChrétien optical system are almost completed and are said to work beyond expectations. But there is less certainty about the eventual outcome of the instrumentation being developed to maintain the direction and stability of the telescope in orbit.

Initial designs for the fine-guidance sensor called for an image dissector able to capture a selected guide star combined with a fixed interferometer to compare the separate images of the star produced. When this proved to be a cumbersome arrangement Perkin-Elmer, the principal contractor for the Optical Telescope Assembly, put forward a more streamlined design which incorporated the moving parts into the interferometer. Once the start selector had found the guide star, the whole fine-guidance system would be locked in place, and directioning control transferred to the gyroscopes which are used to position the space support module within which the optical telescope assembly is contained. The scheme was calculated to operate with a high degree of accuracy.

Unfortunately it was realized at a late stage that, as the fine guidance sensor had a limited near range, by locking it in place the system would be unable to compensate for any sudden torque produced in the system as a whole in reaction to the movement of some other component if the result was a linear displacement of more than about 0.015 arc seconds.

Following this "pointing crisis", the whole system has been redesigned. New feedback has been introduced by keeping the star selector in the interferometer working in an active mode to keep the telescope fixed in its predetermined direction. Several parts of the five scientific

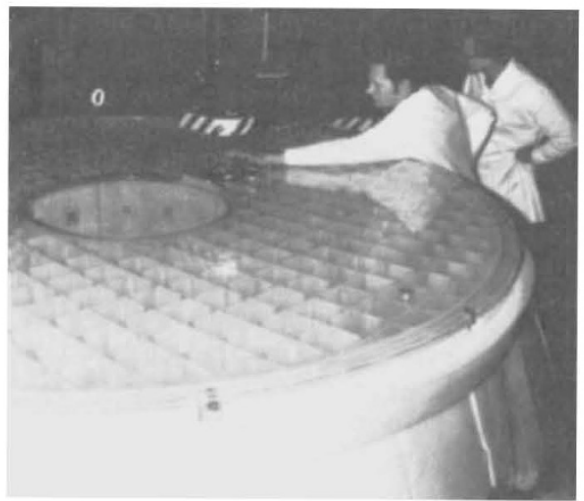

Primary mirror - looking good

instruments being carried are also being altered to reduce the effects of their movement on the rest of the vehicle.

However, the additional movement in the pointing system could still cause problems if either the fine-guidance sensor

\title{
From the frying-pan into the fire?
}

The British Prime Minister, Mrs Margaret Thatcher, announced earlier this week that the Secretary of State for Education and Science since May 1979, Mr Mark Carlisle, has been replaced by Sir Keith Joseph, Secretary of State for Industry during the same period. The changes are part of a substantial reorganization of the British Cabinet.

Mr Carlisle will now become an ordinary Member of Parliament. Sir Keith will remain a member of the Cabinet, in which he has been one of the principal advocates of monetarist policies since the election of the present government, but the post of Secretary of State for Education and Science is usually reckoned to carry with it less political clout than that at industry.

Even so, and in spite of Sir Keith's reputation for agonizing hard and long (and sometimes too long) before making a decision, the arrival of a new minister at the department will be welcomed in higher education. Mr Carlisle's uncompleted business includes the need to respond to the demand of the House of Commons Select Committee on Education for a sight of the or the gyroscopes create some unanticipated resonance in the support structure, something that will only be discovered during the pre-launch phase when a modal survey will be carried out.

The alterations will also mean a slight degradation in the telescope's expected performance. This will still be well within the minimum performance included in the original design specifications; but it will not, at least initially, be as high as it could have been if more time (and development funds) had been available.

Under the original Perkin-Elmer design, for example, the telescope was expected to be able to maintain an accuracy of 0.007 arc seconds over extended periods of time. The new system is designed to an accuracy of 0.012 arc seconds although it is hoped that in practice this can be raised to 0.009 arc seconds. Although much higher than most astronomers need, this will, for example, result in a loss of some image quality in the ultra violet range with the faint-image camera being built by the European Space Agency.

According to project scientist Dr Robert O'Dell, however, the main problems faced by the space telescope are not technical but financial. The development programme costing about $\$ 120$ million a year - is at the stage when delays can have the most significant impact on overall costs.

Late last year NASA reviewed the programme in view of problems that seemed to be emerging at Perkin-Elmer. This set the launch date back by eighteen months to early 1985 , and the total predicted cost was increased by about $\$ 150$ million in 1982 dollars to between $\$ 700$ and $\$ 750$ million.

letters written to him by the chairman of the University Grants committee, Dr Edward Parkes, and the need to respond to the demand by the Committee of ViceChancellors and Principals that funds should be made available to pay for the cost of redundancies among academics forced on the universities in July. The arrival at the Department of Education and Science of a secretary of state free to disown his predecessor's decisions will seem to many universities to be an opportunity for reprieve.

The reshuffle may, however, have come too late for some universities. Those which have already drawn up plans for reducing academic payrolls by compulsory redundancy may find that their compliance is taken as a sign of weakness. The rest are likely now argue that a slower contraction of the university system than decreed will in the long run be more economical.

The Space Telescope remains at the top of NASA's space science priority list. Proposed to Congress by President Carter in 1977 , it is the last "new start" to have escaped budget cuts, and its projected launch date has remained fixed on the 
space shuttle schedule in recent months while others have gradually slipped back.

So far, everyone is being optimistic that the 1985 or possibly an earlier launch date will be met. This will be particularly important to planetary scientists who will need observations from the space telescope early in 1985 to prepare the imaging sequence for the Voyager 2 spacecraft as it approaches its encounter with Uranus on 24 January 1986.

If the programme does slip, NASA could be faced with a rapidly escalating bill as technical crews and scientific facilities are kept standing idle. The major nightmare is that as with the shuttle, budget increases caused by last-minute delays could have a considerable impact on other parts of the space science programme. David Dickson

\section{DNA guidelines}

\section{Voluntary code}

\section{Washington}

In a move that is expected to precipitate the withdrawal of government controls on recombinant DNA research, the National Institutes of Health (NIH) are being provisionally recommended by their Recombinant DNA Advisory Committee (RAC) to turn the safety guidelines which must at present be followed by all those receiving federal funds for such research into a voluntary code of practice.

A resolution passed at a public meeting of the committee in Bethesda, Maryland, last Thursday recommended that, rather than expecting research workers to obey a special set of rules for experiments using recombinant DNA, in general the safety measures to be taken should be comparable with those suggested by, for example, the Center for Disease Control (CDC) for research involving the microorganisms in question.

Changes suggested by RAC in the existing guidelines, first introduced by NIH in 1976, would keep the committee in existence as a forum for public discussion of potential safety problems. Several committee members acknowledged that its function would be primarily social and political, designed to deflect any future local opposition to recombinant DNA research.

Individual universities and research institutions, however, would be free to decide how they administered the guidelines, and would no longer be required by $\mathrm{NIH}$ to do this through a formallyestablished Institutional Biosafety Committee (IBC) with a prescribed membership, as at present. Nor would most experiments require prior approval by IBCs or their equivalent.

RAC's actions followed suggestions by Dr Allan Campbell of Stanford University and Dr David Baltimore of the Massachusetts Institute of Technology, for a substantial easing up both in the containment criteria to be used for different types of experiments, and in the administrative processes required to see that these were followed (Nature 291, 3; 1981). These recommendations were passed to a subcommittee which presented its report to the full committee last week. In general, the members of the subcommittee agreed that there was a good scientific case for a significant reduction in the containment levels for all experiments apart from those known to present a particular type of danger.

In its agreed statement, which will be published in the Federal Register for public comment before being given final consideration by RAC, the full committee suggests that where physical containment levels applicable to non-recombinant DNA experiments exist for either the host or the vector, for example those under revision by CDC, "recombinant DNA experiments should be carried out at containment levels at least as high as those recommended for non-recombinant DNA experiments".

Extensive discussion took place about which types of experiment should be prohibited (or under a voluntary code of practice, should not be carried out) without explicit consideration. Committee members voted that it should no longer be necessary to suggest this either for largescale experiments using more than 10 litres of culture, or for experiments which involved the release of genetically-altered microorganisms into the environment.

However, the committee also agreed that special consideration should still be given to experiments which involve the transfer of drug-resistance traits, as well as work with known toxins, for which specific containment levels would still be recommended.

There was less agreement on how much of an administrative apparatus should be kept in place. Professor Norton Zinder of the Rockefeller University made a strong plea to the committee that, because the scientific basis for imposing strict regulations on research workers seemed to be evaporating, the RAC should consider phasing itself out of existence.

Dr Baltimore responded by saying he felt RAC could continue to play an important role. In the past, for example, congressional legislators had been able to use the existence of the committee to ward off demands for regulatory legislation. In the same way he said, in communities such as Boston where the activities of emerging genetic engineering companies has once again stimulated a fierce public debate over the potential health and environmental risks, the absence of a national focus could stimulate demands for increased local surveillance and control.

The committee as a whole seemed eager to get on with dismantling the regulatory structure that has been built up by NIH. By a vote of 16 members to three, with one abstention, it agreed to a statement recommending revisions to the guidelines that would eliminate their mandatory element, remove the now-redundant section suggesting voluntary compliance by private industry, remove several categories from the list of prohibitions (which would be referred to as "admonitions"), and merely include the statement that "adherence to these stanards by all laboratories using recombinant DNA is recommended". David Dickson

\section{Plant genetics}

\section{Head-hunt threat}

Britain could lose the fruits of research of genetic manipulation with plant material unless steps are taken soon to exploit techniques now being developed. That is the concern of the British Technology Group (formed last month from the former National Research Development Corporation and the National Enterprise Board). The group is especially concerned about commercially promising developments within the Agricultural Research Council's special programme.

The chief concern is that the council's programme has been so successful as to arouse the interest of biotechnology companies in the United States. Representatives from several companies, including Advanced Genetic Science from Greenwich, Connecticut, and Bostonbased Genetics International, have been head-hunting in council institutes. The British Technology Group fears that the US companies will tempt away people and ideas before British industry can make an alternative investment.

Most efforts so far have comprised job offers in the United States and money for fellowships in Britain, but some companies are said also to be considering setting up laboratories in Britain. Joint projects with the Agricultural Research Council are ruled out because of the understanding that the British Technology Group should have first refusal on commercially promising developments by research council scientists.

All parties agree that there is no immediate threat of an exodus of British plant geneticists, but each recognizes that a British initiative is needed fairly urgently if the lure is not to become too great. One of the possibilities being looked at is for a company similar to Celltech; one fear is that even such a company might rob the Agricultural Research Council of staff.

Like Celltech, the new company might begin by supplying monoclonal antibodies for veterinary use, among other things. Research under the Agricultural Research Council's genetic manipulation programme is too long-term, however, to be of immediate application. It includes expressing nitrogen-fixing genes in chloroplast cells, expressing chloroplast genes in Escherichia coli and the cloning of genes specific to barley storage protein. Recent progress in these and other areas, however, seems to have persuaded the American companies that they are worth investing in even now.

Judy Redfearn 